\title{
Gastric Bypass May Promote Weight Loss in Overweight Partners
}

\author{
Floor Aarts, PhD, Nalini N. E. Radhakishun, MD, PhD, Mariska van Vliet, MD, PhD, \\ Rinie Geenen, PhD, Ines A. von Rosenstiel, MD, Chris Hinnen, PhD, \\ Jos H. Beijnen, PhD, Dees P. M. Brandjes, MD, PhD, Michaela Diamant, MD, PhD, \\ and Victor E. A. Gerdes, $M D, P h D$
}

Introduction: Following bariatric surgery, patients are expected to implement diet and lifestyle changes that may be imitated by cohabitating family members. We hypothesize that cohabitating family members will lose weight and improve their eating behavior within 1 year after surgery.

Methods: In this observational prospective study, family members of patients who had gastric bypass surgery ( 88 partners, 20 children $\geq 18$ years old, and 25 children between 12 and 17 years old) were repeatedly assessed. Family members were asked to assess their weight and height before and 3, 6, and 12 months following bariatric surgery, and they filled out the Dutch Eating Behavior Questionnaire.

Results: Between baseline and 1 year following surgery, 49 partners of patients who underwent gastric bypass surgery $(66.2 \%)$ lost weight, $6(8.1 \%)$ remained stable, and $19(25.7 \%)$ gained weight. Body mass index of partners $(P=.002)$, particularly of overweight partners $(P<.001)$ - but not childrenshowed a small, significant decrease over time. No significant changes in eating behavior among partners or children were found.

Conclusion: The study indicates that gastric bypass surgery may have a ripple effect, with body weight in partners of patients decreasing over time. However, there is considerable variation in the postoperative weight loss of partners. (J Am Board Fam Med 2015;28:90-96.)

Keywords: Body Mass Index, Gastric Bypass, Obesity, Weight Loss

The development of obesity is multifactorial, with important roles for sedentary lifestyle, hypercaloric diet, and family factors. ${ }^{1}$ Parental weight has

This article was externally peer reviewed.

Submitted 25 March 2014; revised 15 July 2014; accepted 22 July 2014.

From the Departments of Internal Medicine (FA, MvV, DPMB, VEAG), Pediatrics (NNER, IAvR), Medical Psychology/Hospital Psychiatry (CH), and Pharmacy \& Pharmacology (JHB), Slotervaart Hospital, Amsterdam, the Netherlands; the Department of Clinical and Health Psychology, Utrecht University, Utrecht, the Netherlands (RG); the Health Psychology Section, Department of Health Sciences, University Medical Centre Groningen, Groningen, the Netherlands (CH); the Department of Vascular Medicine, Academic Medical Centre, Amsterdam, the Netherlands (DPMB, VEAG); and the Diabetes Centre/ Department of Internal Medicine, VU University Medical Center, Amsterdam, the Netherlands (MD).

Funding: none.

Conflict of interest: none declared.

Corresponding author: Floor Aarts, $\mathrm{PhD}$, Department of Internal Medicine, Slotervaart Hospital, Louwesweg 6, 1066 EC Amsterdam, the Netherlands (E-mail: Floor.Aarts@ slz.nl). proven to be one of the most important independent predictors of childhood obesity $(17.9 \%$ of children with overweight parents and grandparents are overweight vs $7.9 \%$ with normal weight parents and grandparents ${ }^{2}$ ) and, consequently, of obesity in adulthood., While parents and children share both genetic and environmental factors, data from the Framingham Heart Study showed that if one's partner becomes obese, the likelihood that the other partner will become obese increases by $37 \% .^{5}$

For patients with morbid obesity, gastric bypass surgery is one of the most reliable and effective treatments when previous interventions for achieving and maintaining weight loss have been unsuccessful. ${ }^{6}$ The benefits of a gastric bypass operation include weight loss and reduced comorbidities and overall mortality. ${ }^{6,7}$ Following gastric bypass, patients are instructed to implement diet and lifestyle changes that may lead to partners and children mimicking the altered behaviors of the person who underwent gastric bypass surgery. ${ }^{8}$ 
Although some studies of partners and children of patients who underwent gastric bypass surgery have been performed, ${ }^{9,10}$ only 1 article examined changes in weight and health behavior among patients and their family members in the interval before and 1 year after the operation. ${ }^{8}$ This study did find a decrease in weight among obese adult family members $(\mathrm{n}=50)$ but did not detect significant differences in obese children, perhaps because of the small sample size $(n=15)$. Furthermore, family members received lifestyle counseling (eg, dietary advice, multivitamins, physical exercise advice), which is an intervention in itself. If the family members do not get any lifestyle counseling, they might see only the person who had gastric bypass surgery as "the one with the problem," not themselves. This study adds to the findings of previous studies by monitoring weight change of family members of patients undergoing gastric bypass surgery; the study monitored these changes by including twice as many partners and children, by investigating changes in family members' eating behavior, and by taking measurements preoperatively and at 3 time points postoperatively, without adding an intervention aimed at reducing weight loss in partners.

We hypothesized that family members cohabitating with patients undergoing gastric bypass surgery will lose weight and improve their eating behavior during the first year after the operation. Therefore, we created a prospective observational study to evaluate the weight, height, and eating behavior of family members of patients undergoing gastric bypass surgery both before and 3, 6, and 12 months after the operation.

\section{Methods}

\section{Study Sample}

Patients who underwent gastric bypass surgery at the Slotervaart Hospital (Amsterdam, the Netherlands) in 2012 to 2013 and their cohabitating family members (partner and/or children [12-85 years old]) were asked to participate in the study. Partners and children were excluded if they did not have access to scales or height measurement equipment $(\mathrm{n}=0)$; had an endocrine disorder $(\mathrm{n}=2)$; were treated with medications that may cause significant weight gain or loss, such as glucocorticoids $(n=4)$; participated in an organized weight-reduction program $(\mathrm{n}=0)$; participated in a clinical trial
Figure 1. Gastric Bypass and Weight Loss in Partners study flowchart. Missing indicates that there are missing data for families at that specific time point; excluded indicates the number of families excluded from the study. $n$, number of families.

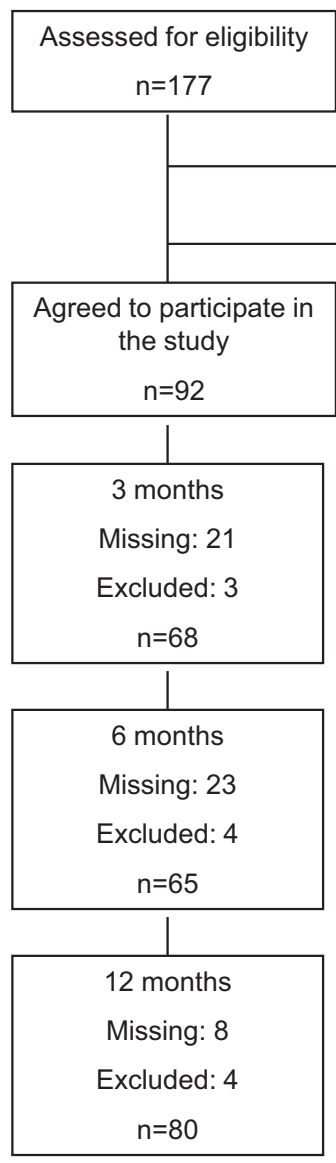

within the 3 months before screening ( $\mathrm{n}=0$ ); received previous surgical treatment for obesity $(\mathrm{n}=8)$; had a history of depressive disorder or other psychiatric disorders $(\mathrm{n}=0)$; was pregnant $(\mathrm{n}=1)$; had a language barrier $(\mathrm{n}=1)$; or had a mental incapacity $(\mathrm{n}=0)$.

\section{Study Design}

This was an observational prospective study with repeated measurements before the operation and 3 , 6 , and 12 months postoperatively. Figure 1 shows a flowchart of the inclusion process. At baseline, 177 families were eligible for participation in the study, of which 92 families agreed to participate. There were no differences in the sex or average number of children between those enrolled in the study and those who were not. Parents of families that enrolled were more often a couple than those who did 
not enroll (97.8\% vs $85.1 \% ; P=.001)$. One year after bariatric surgery, 80 families of patients who had gastric bypass surgery ( 77 partners, 20 children $\geq 18$ years old, and 19 children between 12 and 17 years old) completed the study. There were no differences in sex, marital status, or the average number of children between the families that completed the study and the families that were lost to follow-up.

The patients' weight and height were retrieved from the electronic patient files before surgery and 1 year after the surgery. Family members' weight and height were self-recorded at home, and participants were asked to fill out eating behavior questionnaires before and 3, 6, and 12 months postoperatively. Families were contacted by telephone to remind and instruct them about taking the measurements and completing the questionnaires.

The study was conducted according to the guidelines of the Declaration of Helsinki and was approved by Slotervaart Hospital's Ethics Review Board. Written informed consent was obtained from all participants, and, if between 12 to 17 years old, from their parents/guardians.

\section{Eating Behavior Questionnaire}

An individual's eating behavior was assessed using the validated Dutch Eating Behavior Questionnaire. ${ }^{11}$ The questionnaire includes 13 items about emotional eating (eg, "Does worrying make you feel like eating?"), 10 items about external eating (eg, "Does walking past a candy store make you feel like eating?"), and 10 items about restrained eating (eg, "Do you intentionally eat food that helps you lose weight?"). The questionnaire has a 5-point Likert rating format, ranging from 1 (never) to 5 (very often). The questionnaire has been shown to possess fair internal consistency, satisfactory testretest reliability, and adequate construct and discriminant validity. ${ }^{11}$ In this study, Cronbach $\alpha$ for emotional eating was 0.95 , for external eating, 0.76 , and for restrained eating, 0.94. The theoretical value of $\alpha$ varies from 0 to 1 . An $\alpha$ between 0.6 and 0.7 represents acceptable internal consistency, between 0.7 and 0.9 , good internal consistency, and $\geq 0.9$, excellent internal consistency.

\section{Weight and Height}

Height was measured by participants at home without shoes with their back against the wall looking straight ahead; measurements were taken at approximately the same time of the day. Participants were instructed to measure weight at home with an empty bladder, without shoes, wearing only light clothing, at approximately the same time of the day, using the same scale. Body mass index (BMI) of adults was calculated as weight in kilograms divided by height in meters squared. Normal weight was defined as a BMI $<25 \mathrm{~kg} / \mathrm{m}^{2}$, overweight as a $\mathrm{BMI} \geq 25$ but $<30 \mathrm{~kg} / \mathrm{m}^{2}$, and obesity as a BMI $\geq 30 \mathrm{~kg} / \mathrm{m}^{2}$. The amount of weight loss was calculated by subtracting the baseline weight from the weight measured 1 year following surgery. Then 3 groups were defined: (1) a stable group showing no changes in body weight, (2) a group losing weight (losing $>0.1 \mathrm{~kg}$ ), and (3) a group gaining weight (gaining $>0.1 \mathrm{~kg}$ ).

For children, BMI was standardized using $z$ scores according to Dutch reference values. A BMI $z$ score from 1.1 to 2.3 was classified as overweight and $\geq 2.3$ as obese. ${ }^{12}$ And change in BMI $z$ score was used as an outcome measure.

\section{Statistical Analysis}

Descriptive statistics were computed for demographics, weight, and eating behavior. Means and standard deviations were calculated for continuous variables; frequencies and percentages were used to describe categorical data. Results were stratified by type of family member (partners, children $\geq 18$ years old, children $12-17$ years old). The score distributions of the dependent variables, BMI, and eating behavior (emotional eating, external eating, and restrained eating) were sufficiently normal to allow parametric tests. Variables with a positively skewed distribution were log-transformed or square root transformed before analysis. The univariate correlation between age, sex, and outcome variables (BMI $z$ score and eating behavior) were examined. Demographic variables that significantly correlated with the outcome variables were included in the model.

Linear mixed model analyses with random slopes were used to assess the change in outcome measurements of or BMI, emotional eating, external eating, and restrained eating at baseline and 3, 6 , and 12 months after gastric bypass surgery. A $P$ value $<0.05$ was considered significant. All analyses were performed using SPSS for Windows version 19.0 (SPSS, Inc., Chicago, IL). 
Table 1. Baseline Characteristics Stratified by Family Member

\begin{tabular}{|c|c|c|c|c|}
\hline & Patients $(\mathrm{n}=88)$ & Partners $(\mathrm{n}=83)$ & $\begin{array}{c}\text { Children } \geq 18 \text { Years Old } \\
(\mathrm{n}=26)\end{array}$ & $\begin{array}{l}\text { Children } 12 \text { to } 17 \text { Years Old } \\
\qquad(\mathrm{n}=21)\end{array}$ \\
\hline Male sex, n (\%) & $16(18.2)$ & $67(80.7)$ & $12(46.2)$ & $10(47.6)$ \\
\hline Age (years) & $47.3 \pm 8.4$ & $49.3 \pm 9.4$ & $22.6 \pm 4.2$ & $15.1 \pm 1.4$ \\
\hline Height (m) & $1.71 \pm 0.08$ & $1.78 \pm 0.09$ & $1.78 \pm 0.13$ & $1.69 \pm 0.06$ \\
\hline Weight (kg) & $127.9 \pm 20.2$ & $90.6 \pm 18.8$ & $82.9 \pm 20.9$ & $61.3 \pm 11.9$ \\
\hline BMI $\left(\mathrm{kg} / \mathrm{m}^{2}\right)$ & $43.7 \pm 5.9$ & $28.4 \pm 5.4$ & $25.9 \pm 4.8$ & - \\
\hline $\mathrm{BMI} z$ score & - & - & - & $0.84 \pm 0.96$ \\
\hline Emotional eating & - & $1.6 \pm 0.59$ & $2.0 \pm 0.87$ & $1.8 \pm 0.62$ \\
\hline External eating & - & $2.7 \pm 0.47$ & $2.7 \pm 0.56$ & $2.6 \pm 0.56$ \\
\hline Restrained eating & - & $2.5 \pm 0.91$ & $2.4 \pm 1.1$ & $2.1 \pm 0.79$ \\
\hline Overweight, n (\%) & $0(0)$ & $40(48.2)$ & $9(34.6)$ & $1(4.8)$ \\
\hline Obese, n (\%) & $88(100)$ & $24(28.9)$ & $5(19.2)$ & $1(4.8)$ \\
\hline
\end{tabular}

Data are mean \pm standard deviation unless otherwise indicated.

Body mass index (BMI): overweight adults, $25 \mathrm{~kg} / \mathrm{m}^{2} \geq \mathrm{BMI}<30 \mathrm{~kg} / \mathrm{m}^{2}$; overweight children $2.1>\mathrm{BMI} z$ score $<2.30$; obese adults, $\mathrm{BMI} \geq 30 \mathrm{~kg} / \mathrm{m}^{2}$; obese children: BMI $z$ score $>2.3$, corresponding to $\geq 95$ th percentile for age and sex.

\section{Results}

Baseline characteristics are presented in Table 1. Complete data were obtained from 83 partners and 47 children ( 26 children $\geq 18$ years old, 21 children between 12 and 17 years old) of patients who underwent gastric bypass surgery. Partners were predominantly male (80.7\%), with a mean age of 49.3 years. Nearly $50 \%$ of all children were boys $(48.1 \%$ of children $\geq 18$ years old and $47.6 \%$ of children between 12 and 17 years old).

Pearson's correlations showed that for partners, older age was associated with restrained eating $(r=$ $0.26 ; P<.05)$ and that a higher BMI was associated with emotional, external (both $r=0.26 ; P<.05$ ), and restrained eating $(r=0.30 ; P<.01)$. For children $\geq 18$ years old, older age was associated with BMI $(r=0.57 ; P<.001)$, but no correlations between BMI and eating behaviors were found. Furthermore, for children between 12 and 17 years of age, BMI $z$ score was correlated with both external $(r=0.56 ; P<.05)$ and restrained eating $(r=$ $0.48 ; P=.05)$. No sex-related differences were noted in adults or children.

At baseline, $72.5 \%$ of adult family members ( $\geq 18$ years old) were either overweight $(45.0 \%$ ) or obese $(27.5 \%)$, which are higher rates than those of the general Dutch population (37\% overweight, $11 \%$ obese). ${ }^{13}$ Of children between 12 and 17 years old, $9.6 \%$ were overweight and $4.8 \%$ were obese, which is more comparable to the Dutch population (10\% overweight, $3 \%$ obese), ${ }^{13}$ Furthermore, emotional eating, external eating, and restrained eating by partners and children were comparable with the general Dutch population. ${ }^{11}$

In total, 49 partners of patients who underwent gastric bypass surgery $(66.2 \%)$ lost weight 1 year after the operation, $6(8.1 \%)$ remained stable, and $19(25.7 \%)$ gained weight. Ten children (50\%) $\geq 18$ years old lost weight 1 year after the operation, none remained stable, and $10(50 \%)$ gained weight. Furthermore, 6 children (33.3\%) 12 to 17 years old lost weight, none remained stable, and 12 (66.7\%) gained weight.

Table 2 shows the means and standard deviations of BMI and eating behavior over time among family members. Mixed model analyses showed that body weight $(P=.002)$ and BMI of partners $(P=.002)$ decreased significantly over time. Both body weight (all $P<.01$ ) and BMI (all $P<.05$ ) improved significantly between all time points. Between the baseline assessment and the 1-year postoperative follow-up, the median BMI decreased $0.41 \mathrm{~kg} / \mathrm{m}^{2}$ (interquartile range, $1.39-4.38$; total range, -5.25 to $+5.26 \mathrm{~kg} / \mathrm{m}^{2}$ ), and there was a median weight loss of $1.3 \mathrm{~kg}$ (interquartile range, 4.38 ; range, -12.00 to $+16.30 \mathrm{~kg}$ ) among partners 1 year after surgery.

When divided by weight status (normal weight, overweight, and obese), mixed model analyses showed that body weight (before surgery: mean, 87.32 and standard deviation, 11.74; 1 year after surgery: mean, 85.62 and standard deviation, 11.61; $P<.001$ ) and BMI (before surgery: mean, 27.43 and standard deviation, $1.53 ; 1$ year after surgery: 
Table 2. Changes Over Time for Family Members of Patients Who Underwent Gastric Bypass Surgery

\begin{tabular}{|c|c|c|c|c|c|}
\hline Family Members & Baseline & 3 Months & 6 Months & 1 Year & $\begin{array}{c}P \text { Value } \\
\text { (Over Time) }\end{array}$ \\
\hline \multicolumn{6}{|l|}{ Partners } \\
\hline Body weight (kg) & $90.58(18.78)$ & $88.72(18.51)^{*}$ & $90.21(16.3)^{*}$ & $88.87(16.69)^{*}$ & $<.01$ \\
\hline BMI $\left(\mathrm{kg} / \mathrm{m}^{2}\right)$ & $28.49(5.40)$ & $27.68(5.40)^{*}$ & $28.03(4.86)^{*}$ & $28.00(5.72)^{*}$ & $<.01$ \\
\hline \multicolumn{6}{|l|}{ Eating behavior ${ }^{\dagger}$} \\
\hline Emotional eating & $1.64(0.59)$ & $1.61(0.67)$ & $1.60(0.56)$ & $1.69(0.67)$ & .623 \\
\hline External eating & $2.68(0.47)$ & $2.59(0.48)$ & $2.56(0.54)$ & $2.61(0.54)$ & .410 \\
\hline Restrained eating & $2.50(0.91)$ & $2.64(0.95)$ & $2.55(0.82)$ & $2.62(0.85)$ & .244 \\
\hline \multicolumn{6}{|l|}{ Children $\geq 18$ years old } \\
\hline Body weight (kg) & $82.88(20.87)$ & $83.65(19.23)$ & $86.56(19.62)$ & $80.90(16.42)$ & .206 \\
\hline BMI $\left(\mathrm{kg} / \mathrm{m}^{2}\right)$ & $25.86(4.79)$ & $25.10(4.33)$ & $25.98(5.39)$ & $24.99(3.67)$ & .176 \\
\hline \multicolumn{6}{|l|}{ Eating behavior ${ }^{\dagger}$} \\
\hline Emotional eating & $2.02(0.87)$ & $2.18(0.95)$ & $1.79(0.69)$ & $2.14(0.87)$ & .492 \\
\hline External eating & $2.72(0.55)$ & $2.79(0.68)$ & $2.76(0.49)$ & $2.87(0.56)$ & .765 \\
\hline Restrained eating & $2.41(1.05)$ & $2.64(1.06)$ & $2.30(1.11)$ & $2.44(1.11)$ & .115 \\
\hline \multicolumn{6}{|l|}{ Children $12-17$ years old } \\
\hline Body weight (kg) & $61.31(11.95)$ & $60.10(11.36)$ & $62.74(13.86)$ & $64.45(13.77)$ & $<.05$ \\
\hline $\mathrm{BMI} z \operatorname{score}^{\ddagger}\left(\mathrm{kg} / \mathrm{m}^{2}\right)$ & $0.84(0.96)$ & $0.57(0.87)$ & $0.51(1.32)$ & $0.60(1.23)$ & .191 \\
\hline \multicolumn{6}{|l|}{ Eating behavior ${ }^{\dagger}$} \\
\hline Emotional eating & $1.81(0.62)$ & $1.62(0.25)$ & $1.86(0.89)$ & $1.48(0.39)$ & .225 \\
\hline External eating & $2.57(0.56)$ & $2.57(0.55)$ & $2.79(0.46)$ & $2.64(0.42)$ & .765 \\
\hline Restrained eating & $1.95(0.79)$ & $1.80(0.75)$ & $1.88(0.92)$ & $1.84(0.69$ & .802 \\
\hline
\end{tabular}

Data are mean (standard deviation).

${ }^{*} P<.05$ compared with baseline value.

${ }^{\dagger}$ Eating behavior was assessed using the Dutch Eating Behavior Questionnaire.

${ }^{\ddagger}$ Body mass index (BMI) $z$ score is the standard deviation score of BMI according to Dutch reference values.

mean, 26.76 and standard deviation, $1.74 ; P<.001)$ of overweight partners decreased significantly over time between all time points (all $P<.01)$. No significant improvements occurred among normal weight and obese partners (data not shown).

Changes in body weight and BMI in children $\geq 18$ years of age were not significant over time. In children between 12 and 17 years of age, there was no significant change in BMI $z$ score over time. No significant changes in emotional, external, or restrained eating occurred among partners or children.

\section{Discussion}

This study shows a positive change in the body weight in 2 of every 3 partners living with patients who underwent gastric bypass surgery. At baseline, almost half of the adult family members in our cohort were overweight and one third was obese, which, as expected, is significantly higher than those groups in the general Dutch population. A small but significant reduction in the BMI of part- ners, and of overweight partners in particular, was observed 1 year after bariatric surgery. This is in concordance with a previous study that also observed no change in the weight of lean partners. ${ }^{8}$ However, it did see significant weight loss in 21 obese partners (from 106 to $103 \mathrm{~kg}$; $P<.01$ ) but, in contrast to our results, not in overweight partners. ${ }^{8}$ However, another study observed a mean increase in weight among 30 obese partners of patients who underwent gastric bypass surgery. ${ }^{9}$ Those authors hypothesized that a so-called garbage can effect could cause this: Because of the limited oral intake of the partner who had gastric bypass surgery, the food that is left is eaten by their partner, causing an increase in weight. ${ }^{9}$ In our cohort there was considerable variation in partners' weight change: $66.2 \%$ of partners lost weight, $8.1 \%$ remained stable, and $25.7 \%$ gained weight 1 year after their partner's gastric bypass.

The weight increase in a quarter of the partners in our cohort could be caused by this effect as well. However, our data give more support to the hy- 
Figure 2. The course of weight change across the measurements.

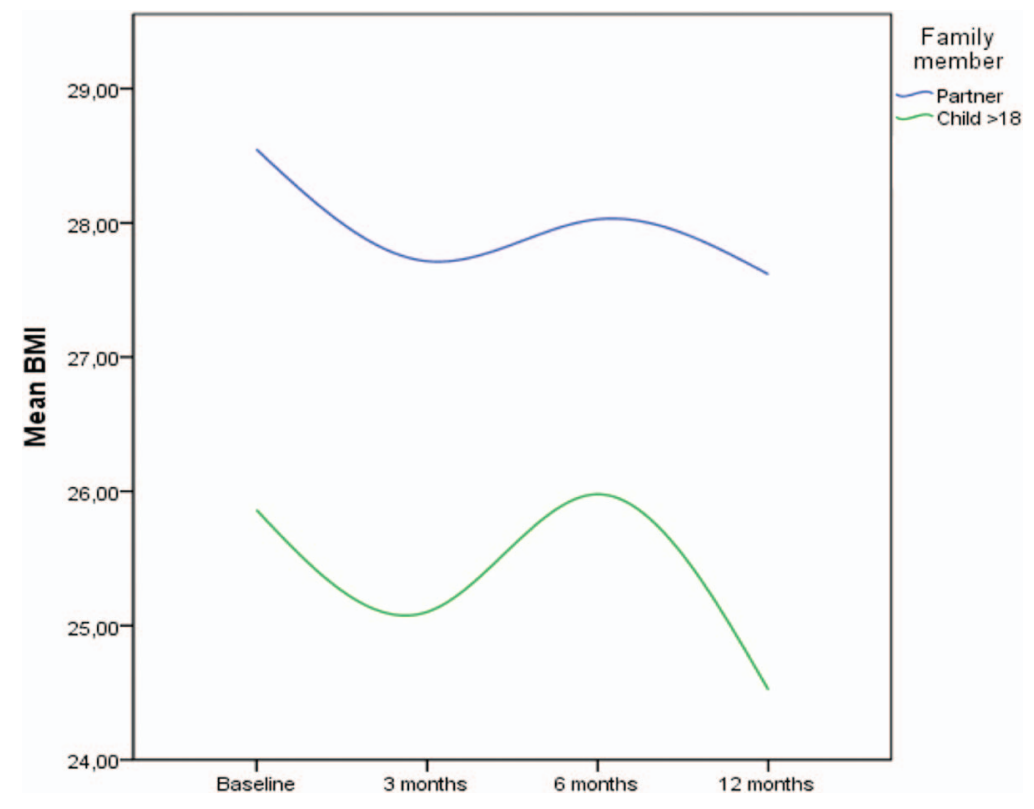

pothesis that the overweight partners mimicked the more healthy lifestyle of the patient who underwent gastric bypass, resulting in a significant decrease in weight over time.

Comparable to the only available study addressing this question, ${ }^{8}$ we found no difference in $\mathrm{BMI} z$ scores or eating behavior in children aged 12 to 17 years. This could be caused by physiology, that is, more energy is needed because of puberty-related growth or the psychological development of children going through puberty. In addition, they undergo progressive individualization, accompanied by newly derived independence, which may make adolescents less sensitive to family-guided behavioral changes; instead, children's eating behavior is affected by the eating behavior of peers proximate to the child. ${ }^{14}$

Indeed, we could not detect a change in eating behavior over time in children or partners of patients who underwent gastric bypass surgery. By contrast, a previous study of 24 adult family members of gastric bypass patients showed an improvement in uncontrolled and emotional eating 1 year after surgery $(P<.05){ }^{8}$ This discrepancy in outcome could not be explained in our study; perhaps it is caused by differences in sample characteristics or the eating behavior questionnaire used.

Although changes in the body weight of partners ${ }^{9}$ and children ${ }^{8}$ of patients who underwent gastric bypass surgery have been described in previous studies, the present study adds to this literature by including twice as many family members and performing measurements at 4 different time points, which is an interesting aspect of any weight loss intervention. If we look at the course of the weight change across the measurements, there is a downand-up trend (Figure 2). However, since at 3 and 6 months account smaller groups for some of this difference, it is difficult to draw strong conclusions based on these numbers. The weight and BMI at these 3 time points, however, were all significantly lower compared with baseline.

Some other limitations have to be acknowledged. First, family members knew that they were participating in a study and had to monitor their weight, which may have had an impact on their weight loss. The periodic contact by telephone to remind and instruct them about the measurements and questionnaires may have promoted their cooperation and weight loss. Second, comparable to a previous study, ${ }^{9}$ weight, height, and eating behavior of family members were obtained through selfassessment. Although family members received extensive instructions regarding these measurements, this may still have caused measurement bias, in particular among children between 12 and 17 years old, who may still be growing. Based on the literature, individuals overestimate their self-reported height and underestimate their self-reported weight, ${ }^{15,16}$ although Christian et $\mathrm{al}^{17}$ showed that 
self-reported weight following bypass surgery was close to the measured weight. Furthermore, since we were interested in BMI change over time, measurement bias may not have influenced our results to a large extent. Third, the follow-up of the study was 1 year, and even though the trend of weight loss seams stable, extending the follow-up period to examine whether this effect is permanent would be preferable. Finally, we did not include a control group that also was monitored in terms of weight, which precludes strong interference of our observational results.

\section{Conclusion}

In the 1 year postoperative interval after gastric bypass surgery, partners of patients showed a small decrease in weight. Prospective studies including a control group that also monitors weight but with partners who did not have bariatric surgery are needed to verify whether the bariatric surgery was the cause of the weight loss in partners of gastric bypass patients.

\section{References}

1. Simopoulos AP. Characteristics of obesity: an overview. Ann N Y Acad Sci 1987;499:4-13.

2. Davis MM, McGonagle K, Schoeni RF, Stafford F. Grandparental and parental obesity influences on childhood overweight: implications for primary care practice. J Am Board Fam Med 2008;21:549-54.

3. Agras WS, Mascola AJ. Risk factors for childhood overweight. Curr Opin Pediatr 2005;17:648-52.

4. Keane E, Layte R, Harrington J, Kearney PM, Perry IJ. Measured parental weight status and familial socio-economic status correlates with childhood overweight and obesity at age 9. PLoS One 2012;7: e43503.

5. Christakis NA, Fowler JH. The spread of obesity in a large social network over 32 years. N Engl J Med 2007;357:370-9.
6. Christou NV, Sampalis JS, Liberman M, et al. Surgery decreases long-term mortality, morbidity, and health care use in morbidly obese patients. Ann Surg 2004;240:416-23.

7. Adams TD, Gress RE, Smith SC, et al. Long-term mortality after gastric bypass surgery. $\mathrm{N}$ Engl J Med 2007;357:753-61.

8. Woodard GA, Encarnacion B, Peraza J, HernandezBoussard T, Morton J. Halo effect for bariatric surgery: collateral weight loss in patients' family members. Arch Surg 2011;146:1185-90.

9. Madan AK, Turman KA, Tichansky DS. Weight changes in spouses of gastric bypass patients. Obes Surg 2005;15:191-4.

10. Watowicz RP, Taylor CA, Eneli IU. Lifestyle behaviors of obese children following parental weight loss surgery. Obes Surg 2013;23:173-8.

11. van Strien T, Frijters JER, Bergers GPA, Defares PB. The Dutch Eating Behaviour Questionnaire (DEBQ) for assessment of restrained, emotional, and external eating behaviour. Int J Eat Disord 1986;5: 295-315.

12. Fredriks AM, van Buuren S, Wit JM, VerlooveVanhorick SP. Body index measurements in 1996-7 compared with 1980. Arch Dis Child 2000;82:107-12.

13. van Hilten O, Voorrips LE. Gezondheid en zorg in beeld. In Gezondheid en Zorg in Cijfers. Den Haag/ Heerlen: Centraal Bureau voor statistiek; 2012.

14. Wouters EJ, Larsen JK, Kremers SP, Dagnelie PC, Geenen R. Peer influence on snacking behavior in adolescence. Appetite 2010;55:11-7.

15. Pursey K, Burrows TL, Stanwell P, Collins CE. How accurate is web-based self-reported height, weight, and body mass index in young adults? J Med Internet Res 2014;16:e4.

16. Connor Gorber S, Tremblay M, Moher D, Gorber B. A comparison of direct vs. self-report measures for assessing height, weight and body mass index: a systematic review. Obes Rev 2007;8:307-26.

17. Christian NJ, King WC, Yanovski SZ, Courcoulas AP, Belle SH. Validity of self-reported weights following bariatric surgery. JAMA 2013;310:2454-6. 